\title{
(C) OPEN ACCESS \\ Presence of anticitrullinated protein antibodies in a large population-based cohort from the Netherlands
}

\author{
A van Zanten, ${ }^{1}$ S Arends, ${ }_{1}^{1}$ C Roozendaal, ${ }_{1}^{2}$ P C Limburg, ${ }^{2} \mathrm{~F} \mathrm{Maas,}{ }^{1} \mathrm{~L} \mathrm{~A}$ Trouw $^{3}$ \\ R E M Toes, ${ }^{3}$ T W J Huizinga, ${ }^{3}$ H Bootsma, ${ }^{1}$ E Brouwer $^{1}$
}

Handling editor Tore K Kvien

- Additional material is

published online only. To view please visit the journal online (http://dx.doi.org/10.1136/ annrheumdis-2016-209991).

'Department of Rheumatology and Clinical Immunology, Groningen, The Netherlands 2Department of Laboratory Medicine, University Medical Center Groningen, University of Groningen, Groningen, The Netherlands

${ }^{3}$ Department of Rheumatology, LUMC, Leiden, The Netherlands

Correspondence to Dr E Brouwer, University Medical Center Groningen Rheumatology and Clinical Immunology, P.O. Box 30001, Groningen 9700 RB, The Netherlands:

e.brouwer@umcg.nl

Received 31 May 2016 Revised 18 November 2016 Accepted 20 November 2016 Published Online First

2 January 2017

\section{CrossMark}

To cite: van Zanten $A$, Arends S, Roozendaal C, et al. Ann Rheum Dis 2017:76:1184-1190.

\section{ABSTRACT}

Objectives To determine the prevalence of anticitrullinated protein antibodies (ACPAs) and their association with known rheumatoid arthritis (RA) risk factors in the general population.

Methods Lifelines is a multidisciplinary prospective population-based cohort study in the Netherlands. Crosssectional data from 40136 participants were used. The detection of ACPA was performed by measuring antiCCP2 on the Phadia-250 analyser with levels $\geq 6.2 \mathrm{U} / \mathrm{mL}$ considered positive. An extensive questionnaire was taken on demographic and clinical information, including smoking, periodontal health and early symptoms of musculoskeletal disorders. RA was defined by a combination of self-reported RA, medication use for the indication of rheumatism and visiting a medical specialist within the last year.

Results of the total 40136 unselected individuals, $401(1.0 \%)$ had ACPA level $\geq 6.2 \mathrm{U} / \mathrm{mL}$. ACPA positivity was significantly associated with older age, female gender, smoking, joint complaints, RA and first degree relatives with rheumatism. Of the ACPA-positive participants, $22.4 \%$ had RA $(15.2 \%$ had defined RA according to our criteria and $7.2 \%$ self-reported RA only). In participants without RA, $311(0.8 \%)$ were ACPA-positive. In the non-RA group, older age, smoking and joint complaints remained significantly more frequently present in ACPA-positive compared with ACPA-negative participants.

Conclusions In this large population-based study, the prevalence of ACPA levels $\geq 6.2 \mathrm{U} / \mathrm{mL}$ was $1.0 \%$ for the total group and $0.8 \%$ when excluding patients with RA. Older age, smoking and joint complaints were more frequently present in ACPA-positive Lifelines participants. To our knowledge, this study is the largest study to date on ACPA positivity in the general, mostly Caucasian population.

\section{INTRODUCTION}

Rheumatoid arthritis (RA) is a chronic autoimmune disease primarily targeting the joints. ${ }^{1}$ It is thought that early treatment with disease-modifying antirheumatic drugs (DMARDs) and possibly steroids can prevent progression of the disease and may even change or prevent the development of erosive disease. $^{2}$ A systemic review in early RA demonstrated that longer symptom duration is associated with more radiographic progression and lower chance of DMARD-free sustained remission, supporting the idea of a therapeutic 'window of opportunity'. ${ }^{3}$ Early detection of RA is therefore crucial.
Previous studies have shown that persons with arthralgia are at risk for developing RA. ${ }^{4}$ This risk is even higher when the arthralgia is combined with anticitrullinated protein antibody (ACPA) positivity. ${ }^{5}$ Patients with clinically suspected arthralgia who show subclinical inflammation on MRI were more often ACPA-positive than those without inflammation on MRI, and were at high risk of developing arthritis. ${ }^{6}$ Individuals with new nonspecific musculoskeletal symptoms but without clinical synovitis were at high risk of rapidly progressing to RA when they tested ACPA-positive.? Therefore, ACPA status can provide important information on both diagnosis and prognosis. ${ }^{4-10}$

Depending on the method of ACPA detection and the cut-off value used, $55-91 \%$ of patients with RA are considered ACPA-positive compared with $0-9 \%$ of healthy control subjects. ${ }^{11-15}$ It has been shown that the switch to ACPA positivity can occur up to 10 years before a patient develops arthritis. Early serum samples from patients with classified RA that were blood bank donors were ACPA-positive in $31-41 \%$ of cases. ${ }^{11} 15 \quad 16$ Similarly, first-degree relatives (FDRs) are more likely ACPA-positive than regular controls. ${ }^{12-14} 17$

In a prospective study of 374 individuals who reported arthralgia and had a positive ACPA and/or IgM-rheumatoid factor (RF) status, 35\% developed arthritis after a median follow-up of 12 months. Patients who developed arthritis were more often ACPA-positive. However, the presence of antibodies alone had insufficient predictive power and needed to be combined with other clinical parameters. ${ }^{5}$ The European League Against Rheumatism Standing Committee on Investigative Rheumatology has pointed out that better insights in early symptoms, ACPA testing and risk factors from patient history are necessary for the development of a predictive model for RA in the years to come. ${ }^{18} 19$

To date, little is known about the presence of ACPA in the general population. One recent population-based study in Japan $(n=9575)$ showed an ACPA positivity prevalence of $1.7 \% 0^{20}$ and a Turkish study $(n=941)$ showed a prevalence of $1.0 \% .^{21}$ So far, only one other population-wide study has been published on the prevalence of ACPA positivity in Europe. In this Swedish twin study $(\mathrm{n}=12590) \quad 2.8 \%$ were ACPA-positive, including patients with RA. ${ }^{22}$ The exact relationship between known RA risk factors, such as age, gender, tobacco, joint complaints and having FDR with $\mathrm{RA}^{20} 2324$ and the development of ACPA positivity needs to be further investigated. ${ }^{25}$ 
The aim of the present study was to determine the prevalence of ACPA positivity on a population level and to determine its association with known RA risk factors. In this respect, we investigated whether previously described risk factors for RA and ACPA development were also more often present in individuals who were ACPA-positive within the Lifelines general population.

\section{MATERIALS AND METHODS}

\section{Study design and study population}

Lifelines is a multidisciplinary prospective population-based cohort study examining in a unique three-generation design the health and health-related behaviours of 167729 persons living in the north-east region of the Netherlands. It employs a broad range of investigative procedures in assessing the biomedical, sociodemographic, behavioural, physical and psychological factors which contribute to the health and disease of the general population, with a special focus on multimorbidity and complex genetics. Lifelines is a facility that is open for all researchers. Information on application and data access procedure is summarised on http://www.Lifelines.net.

Participants were recruited with the help of general practitioners from both rural and non-rural areas and from different economic classes. Participants were then asked to invite their family members, making it into a three-generation populationbased cohort. ${ }^{26}$ This cohort well represents the northern, mostly Caucasian, population of the Netherlands. ${ }^{27}$

Data for the present study were acquired at baseline visits (2012-2013). Participants under 18 years of age were excluded. An extensive questionnaire was handed in, physical examination was performed and serum blood samples were collected. The family history was obtained at the first follow-up visit 1.5 years later. $^{26}$

The Lifelines Cohort Study was conducted according to the principles of the Declaration of Helsinki, approved by the local ethics committee of the University Medical Center Groningen (UMCG), and all participants provided written informed consent to participate in this study.

\section{ACPA measurement}

The detection of ACPA was performed by measuring anti-CCP2 (by EliA-cyclic citrullinated peptide (CCP) test) on the Phadia-250 analyser. The measuring range (detection limit, upper limit) for EliA CCP is from 0.4 EliA U/mL to $\geq 340$ EliA $\mathrm{U} / \mathrm{mL}$.

ACPA-CCP2 levels $\geq 6.2 \mathrm{U} / \mathrm{mL}$ were considered positive, based on data of 400 apparently healthy controls obtained from ThermoFisher Scientific. The cut-off value that is appropriate to detect ACPA in the healthy population is not clear. As we wanted to use the test to detect ACPA and not as a diagnostic test for RA, the 99 -centile cut-off value of $\geq 6.2 \mathrm{U} / \mathrm{mL}$ was chosen. Analyses were also done using the 95 -centile cut-off value of $\geq 4.3 \mathrm{U} / \mathrm{mL}$ and the manufacturer's cut-off value for RA of $\geq 10 \mathrm{U} / \mathrm{mL}$.

\section{Assessment of risk factors}

Risk factors for RA and ACPA were determined using literature analysis on PubMed. Access to data on these risk factors was then assessed. Risk factors that could be included in the analyses were age, gender, body mass index (BMI), use of tobacco, alcohol, fish and/or sugar-sweetened soft drinks, periodontitis, joint complaints and FDRs with rheumatism. For women nulliparity, menopausal status and hormone use, regular menses and early menarche were assessed. Definitions of these risk factors are shown in online supplementary table S1.

\section{Definition of RA}

Patients with RA were identified using data from the questionnaires. A participant was classified as a self-reported patient with RA if the question on having RA was answered positive. A participant was classified as patient with defined RA if there was either a combination of self-reported RA and the use of a DMARD for the indication of 'rheumatism' or a combination of self-reported RA, the use of steroids and/or non-steroidal antiinflammatory drugs (NSAIDs) for the indication of 'rheumatism' and having been to a medical specialist within the last year. An overview of included DMARDs and NSAIDs is given in online supplementary table S2.

\section{Statistical analysis}

Results were expressed as percentage of participants, mean \pm SD or median (IQR) for categorical, normally distributed and nonnormally distributed data, respectively.

To assess whether the risk factors found in literature were correlated with ACPA positivity, participants were stratified according to ACPA positivity. We performed the same analyses excluding all patients with RA and defined patients with RA from the total populations. For all three analyses, $\chi^{2}$ tests, Mann-Whitney $U$ tests and univariable logistic regression were performed to assess the differences.

Multivariable logistic regression (enter method, forward selection and backward elimination) was performed to assess which factors were independent predictors of ACPA positivity. Parameters were added into the model if they were found to be significantly associated with ACPA positivity in the previous analyses. If there was more than one variable for the same factor, the strongest predictor of ACPA positivity was used. Multivariable analysis was performed both for the entire group and excluding defined or self-reported patients with RA.

Statistical analysis was performed with IBM SPSS Statistics V.22 (SPSS, Chicago, Illinois, USA). p Values $\leq 0.05$ were considered statistically significant.

\section{RESULTS}

\section{Study population}

In total, 40136 participants were recruited for this study, of whom 23256 (58\%) were female. The mean age was 44 (range 18-92). Among these participants, 838 (2.1\%) had self-reported RA and $138(0.3 \%)$ were defined as having RA (table 1 , online supplementary table S3).

\section{Distribution of ACPA-CCP2 levels}

Of all participants, $401(1.0 \%)$ had an ACPA-CCP2 level $\geq 6.2 \mathrm{U} / \mathrm{mL}, 666(1.7 \%)$ had an ACPA-CCP2 level $\geq 4.3$ and 306 $(0.8 \%)$ had an ACPA-CCP2 level $\geq 10 \mathrm{U} / \mathrm{mL}$. The detailed distribution of ACPA levels among participants is presented in table 2 .

ACPA positivity $(\geq 6.2 \mathrm{U} / \mathrm{mL})$ was seen in $90(10.7 \%)$ of patients with self-reported RA and 61 (44.2\%) of patients with defined RA. In participants without RA (non-RA group), 311 $(0.8 \%)$ were ACPA-positive. The prevalence of both ACPA positivity and RA increased with age (table 3 ).

\section{ACPA-positive versus ACPA-negative participants}

ACPA-positive $(\geq 6.2 \mathrm{U} / \mathrm{mL}$ ) participants were significantly older and more often female compared with the ACPA-negative participants. Furthermore, ACPA-positive participants had more pack years of smoking and had less often never smoked. Joint complaints and FDRs with rheumatism were also significantly more often reported. Moreover, ACPA-positive participants had 
Table 1 Baseline characteristics: all participants

\begin{tabular}{ll}
\hline & All (n=40 136) \\
\hline Age (years) & $44(34-51)$ \\
\hline Gender (female) & $58 \%$ \\
\hline BMI (kg/m ${ }^{2}$ ) & $25(23-28)$ \\
\hline Obesity & $15 \%$ \\
\hline Smoking (pack years) & $0(0-8)$ \\
Smoking status & \\
\hline \multicolumn{1}{|l}{ Never smoker } & $49 \%$ \\
\hline Former smoker & $30 \%$ \\
\hline Current smoker & $21 \%$ \\
\hline Alcohol intake (g/day) & $3(0-11)$ \\
\hline Fish intake (servings/month) & $5(2-9)$ \\
\hline Sugar-sweetened soft drink intake (glasses/month) & $6(0-22)$ \\
\hline Periodontitis (self-reported) & $12 \%$ \\
\hline Joint complaints: pain and/or stiffness in hands and/or feet & $21 \%$ \\
\hline Joint complaints: both pain and stiffness in hands and/or feet & $12 \%$ \\
\hline FDR with rheumatism & $14 \%$ \\
\hline Self-reported RA & $2.1 \%$ \\
\hline Defined RA & $0.3 \%$ \\
\hline In women (n=23 256) & \\
\hline Nulliparity & $27 \%$ \\
\hline Menopausal status, categories & \\
\hline Premenopausal & $63 \%$ \\
\hline Postmenopausal and hormone use & $4 \%$ \\
\hline Postmenopausal and no hormone use & $33 \%$ \\
\hline Regular menses & $77 \%$ \\
\hline Age of menarche $\leq 10$ & $2 \%$ \\
\hline Data a & \\
\hline
\end{tabular}

Data are presented as median (IQR) for continuous variables and percentages for categorical variables

$\mathrm{BMI}$, body mass index; FDR, first-degree relative; RA, rheumatoid arthritis.

\begin{tabular}{|c|c|c|c|c|}
\hline & $\begin{array}{l}\text { All } \\
(n=40136 ; \%)\end{array}$ & $\begin{array}{l}\text { No RA } \\
(\mathrm{n}=39298 ; \%)\end{array}$ & $\begin{array}{l}\text { Self-reported } \\
\text { RA ( } \mathrm{n}=838 ; \%)\end{array}$ & $\begin{array}{l}\text { Defined RA } \\
(\mathrm{n}=138 ; \%)\end{array}$ \\
\hline$\geq 6.2 \mathrm{U} / \mathrm{mL}$ & 1.0 & 0.8 & 10.7 & 44.2 \\
\hline$<4.3 \mathrm{U} / \mathrm{mL}$ & 98.3 & 98.5 & 88.5 & 55.1 \\
\hline $4.3-6.2 \mathrm{U} / \mathrm{mL}$ & 0.7 & 0.7 & 0.8 & 0.7 \\
\hline $6.2-10 \mathrm{U} / \mathrm{mL}$ & 0.2 & 0.2 & 0.4 & 0.7 \\
\hline$\geq 10 \mathrm{U} / \mathrm{mL}$ & 0.8 & 0.6 & 10.3 & 43.5 \\
\hline
\end{tabular}

$R A$, rheumatoid arthritis.

substantially more frequently self-reported or defined RA (table 4). When using a cut-off value of $\geq 4.3 \mathrm{U} / \mathrm{mL}$ or $\geq 10 \mathrm{U} / \mathrm{mL}$, similar results were found. Additionally for $\geq 10 \mathrm{U} / \mathrm{mL}$, ACPA-positive participants reported significantly less use of sugar-sweetened soft drinks and women were less often nulliparous (data not shown).

In the population without RA or self-reported RA, older age, smoking and joint complaints remained associated with ACPA positivity $(\geq 6.2 \mathrm{U} / \mathrm{mL}$ ) (table 5 ). In this group, gender, BMI, alcohol intake, fish intake, sugar-sweetened soft drink intake, periodontitis and FDR with rheumatism were comparable between ACPA-positive and ACPA-negative participants. Within the female study population, nulliparity, menopausal status and hormone use, early menarche and regular menses were not
Table 3 The distribution of the Lifelines population, anticitrullinated protein antibodies (ACPA) positivity, self-reported rheumatoid arthritis (RA) and defined RA among different age groups

\begin{tabular}{lllll}
\hline Age (years) & $\begin{array}{l}\text { Lifelines } \\
\text { population (\%) }\end{array}$ & $\begin{array}{l}\text { ACPA positivity } \\
(\geq 6.2 \mathrm{U} / \mathrm{mL} ; \%)\end{array}$ & $\begin{array}{l}\text { Self-reported } \\
\text { RA (\%) }\end{array}$ & $\begin{array}{l}\text { Defined } \\
\text { RA (\%) }\end{array}$ \\
\hline $18-30$ & 16.5 & 0.6 & 0.5 & 0.1 \\
\hline $30-40$ & 19.7 & 0.8 & 1.0 & 0.1 \\
$40-50$ & 34.4 & 0.9 & 2.0 & 0.3 \\
$50-60$ & 19.7 & 1.4 & 3.3 & 0.7 \\
$60+$ & 9.7 & 1.5 & 5.0 & 0.8 \\
\hline
\end{tabular}

associated with ACPA positivity. When a cut-off value of $\geq 4.3$ $\mathrm{U} / \mathrm{mL}$ or $\geq 10 \mathrm{U} / \mathrm{mL}$ was used, similar results were found.

\section{Independent predictors of ACPA positivity}

Using multivariable analysis, pack years of smoking was the strongest smoking variable predicting ACPA positivity and not smoking status (never, former or current). Gender, pack years of smoking and joint complaints were independent predictors of ACPA positivity (table 6). When excluding self-reported and/or defined RA participants, only gender and pack years remained statistically significant.

\section{DISCUSSION}

In this large cross-sectional population-based study $(n=40136)$, the prevalence of ACPA positivity was $1.0 \%$ on a population level and $0.8 \%$ when excluding RA participants, using ACPA-CCP2 $\geq 6.2 \mathrm{U} / \mathrm{mL}$ (99th centile) as the cut-off point.

Three previous studies investigated the prevalence of ACPA positivity in the general population. In a Japanese study ${ }^{20}$ $(\mathrm{n}=9575)$, the reported prevalence was $1.7 \%$ in autoimmune disease-free volunteers aged 30-75 years using a Japanese CCP2-kit. A Turkish study ${ }^{21}(\mathrm{n}=941)$ found a prevalence of $1.0 \%$ in a healthy population using a EuroDiagnostica secondgeneration anti-CCP antibody assay. A twin study in Sweden found an $(n=12590)$ ACPA positivity (including patients with RA) of $2.8 \%$ using an anti-CCP2 ELISA EuroDiagnostica assay. $^{22}$ However, as the first two studies were performed in non-Caucasian populations and all studies used different ACPA-CCP assays with different cut-off levels, it is difficult to compare their results with our study.

In our study population, ACPA positivity was significantly associated with several risk factors for RA and/or ACPA as found in literature.

First, we found an association between older age and ACPA positivity, both in the entire group and in the non-RA group. In agreement with our study, the Japanese study found that in non-RA individuals ACPA positivity was associated with older age. $^{20}$

Second, we found an association between female gender and ACPA positivity, which has not yet been well documented, although RA is more prevalent among women. ${ }^{28}$ In our study, female gender remained significantly associated with ACPA positivity after correcting for age, smoking and joint complaints. However, when excluding patients with RA, female gender was no longer associated with ACPA positivity.

Third, we found an association of both smoking status and pack years with ACPA positivity, which was reported in previous studies as well. A Malaysian case-control study $(n=1056$ vs 1416) found that ever-smokers had an increased risk of developing ACPA-positive RA compared with never smokers. A relation 
Table 4 Baseline characteristics of all participants; ACPA-positive ( $\geq 6.2 \mathrm{U} / \mathrm{mL})$ versus ACPA-negative

\begin{tabular}{|c|c|c|c|c|}
\hline & All $(n=40$ 136) & $\begin{array}{l}\text { ACPA-positive } \\
\text { participants }(n=401)\end{array}$ & $\begin{array}{l}\text { ACPA-negative } \\
\text { participants }(n=39735)\end{array}$ & $\mathrm{p}$ Value \\
\hline Age (years) & $44(34-51)$ & $48(39-54)$ & $44(34-51)$ & $<0.001$ \\
\hline Gender (female) & $58 \%$ & $65 \%$ & $58 \%$ & 0.005 \\
\hline Obesity & $15 \%$ & $14 \%$ & $15 \%$ & 0.611 \\
\hline Smoking: pack years & $0(0-8)$ & $2(0-13)$ & $0(0-8)$ & $<0.001$ \\
\hline Former smoker & $30 \%$ & $36 \%$ & $30 \%$ & \\
\hline Current smoker & $21 \%$ & $25 \%$ & $21 \%$ & \\
\hline Alcohol (g/day) & $3(0-11)$ & $4(0-11)$ & $3(0-11)$ & 0.571 \\
\hline Alcohol intake, categories & & & & 0.396 \\
\hline None to $5 \mathrm{~g} /$ day & $59 \%$ & $56 \%$ & $59 \%$ & \\
\hline Sugar-sweetened soft drink intake (glasses/month) & $6(0-22)$ & $5(0-17)$ & $6(0-22)$ & 0.053 \\
\hline Periodontitis (self-reported) & $12 \%$ & $14 \%$ & $12 \%$ & 0.263 \\
\hline Joint complaints: pain and/or stiffness in hands and/or feet & $21 \%$ & $39 \%$ & $21 \%$ & $<0.001$ \\
\hline Joint complaints: both pain and stiffness in hands and/or feet & $12 \%$ & $29 \%$ & $12 \%$ & $<0.001$ \\
\hline FDR with rheumatism & $14 \%$ & $18 \%$ & $14 \%$ & 0.014 \\
\hline Self-reported RA & $2 \%$ & $22 \%$ & $2 \%$ & $<0.001$ \\
\hline Defined RA & $0 \%$ & $15 \%$ & $0 \%$ & $<0.001$ \\
\hline \multicolumn{5}{|l|}{ In women ( $n=23$ 256) } \\
\hline Nulliparity & $27 \%$ & $23 \%$ & $27 \%$ & 0.182 \\
\hline Menopausal status, categories & & & & 0.454 \\
\hline Premenopausal & $63 \%$ & $68 \%$ & $63 \%$ & \\
\hline
\end{tabular}

Data are presented as median (IQR) for continuous variables and percentages for categorical variables.

ACPA, anticitrullinated protein antibodies; BMI, body mass index; FDR, first-degree relative; RA, rheumatoid arthritis.

between pack years and the risk of ACPA-positive RA was also seen, with an OR of 3.3 for $<20$ pack years and an OR of 5.2 for at least 20 pack years. ${ }^{29}$ This is in contrast to the Japanese population-based study, where only a significant association between the amount of smoking and high levels of ACPA was found. ${ }^{20}$

Finally, joint complaints were found to be an independent risk factor for ACPA positivity, even with the limited joint complaint questions that were asked to the participants. Also, in non-RA participants the presence of joint complaints stayed significantly different between ACPA-positive and ACPA-negative participants after correcting for age, gender and smoking.

FDRs of patients with RA were found to be more often ACPA-positive. ${ }^{14}$ In our study population, having FDRs with rheumatism was also associated with ACPA positivity. However, in the non-RA group this was no longer the case. One possible explanation for FDR with rheumatism not being associated with ACPA positivity in the non-RA group in our study would be the questionnaires asking for FDRs with rheumatism instead of RA.

Other risk factors for RA and ACPA as found in literature were not significantly associated with ACPA positivity in our Lifelines population. In the Nurses' Health Study, overweight and BMI were significantly associated with RA. ${ }^{30}$ In our study,
BMI was not associated with ACPA positivity. Alcohol non-use has been associated with ACPA positivity and/or higher ACPA titres and self-reported periodontitis has been associated with RA in previous studies, ${ }^{14}{ }^{31-33}$ but we could not confirm these findings. Periodontitis was assessed in the Lifelines population using a questionnaire and may therefore have not been fully accurate. Furthermore, it has been described that within a person's diet fish intake $(n=1889)$ would protect against and sugar-sweetened soft drinks $(n=79570)$ would be a risk factor for RA. ${ }^{34}$ We could not replicate these results.

The female-based variables nulliparity, menopausal status, regular menses and early menarche were all not significantly associated with ACPA positivity, both in the entire study population as well as after excluding RA participants. These results are in agreement with recent literature. ${ }^{28}$

The main limitations of the present study were first the fact that the ACPA cut-off value is not a 'fixed' value and second that it could not be verified by medical records whether participants had RA. The ACPA cut-off value was difficult to determine since all tests and their specificities and sensitivities are based on using the test as a diagnostic tool for RA. However, after consulting the manufacturer and taking into account data they provided on ACPA levels of 400 apparently healthy 
Table 5 Baseline characteristics of all participants without RA; ACPA-positive ( $\geq 6.2 \mathrm{U} / \mathrm{mL})$ versus ACPA-negative

\begin{tabular}{|c|c|c|c|c|}
\hline & All $(n=39298)$ & $\begin{array}{l}\text { ACPA-positive } \\
\text { participants }(n=311)\end{array}$ & $\begin{array}{l}\text { ACPA-negative } \\
\text { participants ( } n=38 \text { 987) }\end{array}$ & $\mathrm{p}$ Value \\
\hline Age (years) & $44(34-51)$ & $46(35-52)$ & $44(34-51)$ & 0.017 \\
\hline Gender (female) & $58 \%$ & $62 \%$ & $58 \%$ & 0.103 \\
\hline BMI $\left(\mathrm{kg} / \mathrm{m}^{2}\right)$ & $25(23-28)$ & $25(23-28)$ & $25(23-28)$ & 0.834 \\
\hline Obesity & $15 \%$ & $13 \%$ & $15 \%$ & 0.444 \\
\hline Smoking: pack years & $0(0-8)$ & $1(0-11)$ & $0(0-8)$ & $<0.001$ \\
\hline Smoking status & & & & 0.006 \\
\hline Never smoker & $49 \%$ & $40 \%$ & $49 \%$ & \\
\hline Former smoker & $30 \%$ & $35 \%$ & $30 \%$ & \\
\hline Current smoker & $21 \%$ & $25 \%$ & $21 \%$ & \\
\hline Alcohol (g/day) & $3(0-11)$ & $3(0-9)$ & $3(0-11)$ & 0.861 \\
\hline Alcohol intake, categories & & & & 0.499 \\
\hline None to $5 \mathrm{~g} /$ day & $59 \%$ & $57 \%$ & $59 \%$ & \\
\hline 5 g/day to $<10 \mathrm{~g} /$ day & $16 \%$ & $18 \%$ & $16 \%$ & \\
\hline $10 \mathrm{~g} /$ day or more & $25 \%$ & $24 \%$ & $25 \%$ & \\
\hline Fish intake (servings/month) & $5(2-9)$ & $5(2-9)$ & $5(2-9)$ & 0.754 \\
\hline Sugar-sweetened soft drink intake (glasses/month) & $6(0-22)$ & $6(0-20)$ & $6(0-22)$ & 0.270 \\
\hline Periodontitis (self-reported) & $12 \%$ & $14 \%$ & $12 \%$ & 0.284 \\
\hline Joint complaints: pain and/or stiffness in hands and/or feet & $20 \%$ & $26 \%$ & $20 \%$ & 0.018 \\
\hline Joint complaints: both pain and stiffness in hands and/or feet & $11 \%$ & $15 \%$ & $11 \%$ & 0.026 \\
\hline FDR with rheumatism & $14 \%$ & $15 \%$ & $14 \%$ & 0.476 \\
\hline \multicolumn{5}{|l|}{ In women ( $n=22727)$} \\
\hline Nulliparity & $27 \%$ & $28 \%$ & $27 \%$ & 0.926 \\
\hline Menopausal status, categories & & & & 0.145 \\
\hline Premenopausal & $63 \%$ & $73 \%$ & $63 \%$ & \\
\hline Postmenopausal and hormone use & $4 \%$ & $4 \%$ & $4 \%$ & \\
\hline Postmenopausal and no hormone use & $33 \%$ & $23 \%$ & $34 \%$ & \\
\hline Regular menses & $78 \%$ & $78 \%$ & $78 \%$ & 0.984 \\
\hline Age of menarche $\leq 10$ & $2 \%$ & $3 \%$ & $2 \%$ & 0.302 \\
\hline
\end{tabular}

Data are presented as median (IQR) for continuous variables and percentages for categorical variables.

ACPA, anticitrullinated protein antibodies; BMI, body mass index; FDR, first-degree relative; RA, rheumatoid arthritis.

controls, we decided that $6.2 \mathrm{U} / \mathrm{mL}$ (99th centile) is an appropriate cut-off value. This cut-off value was lower than the cut-off value used in the diagnostic test for RA $(\geq 10 \mathrm{U} / \mathrm{mL})$ in order to get an insight into the presence of ACPA.

Second, many people regard themselves as having RA when they experience joint complaints, but they have not always been diagnosed by a doctor. Therefore, we checked RA-specific medication use and visits to a medical specialist in these patients with self-reported RA. As this database was large, the indexing that was used to find the medication of interest may have missed some patients with RA. To make the selection of patients with defined RA more secure, the indications of the drugs were checked by hand. Since ACPA positivity shows a steep curve from non-RA to self-reported RA to defined RA, we concluded that our definition is a good estimate for RA. However, the prevalence we found for defined RA is somewhat low, which makes it likely that some patients were missed using this definition. ${ }^{36}$ Additionally, the prevalence of ACPA positivity was only $44 \%$ in our defined RA population, whereas previous literature has shown that $55-91 \%$ of patients with RA are considered ACPA-positive. ${ }^{11-15}$ This means that our defined RA group likely also contains some individuals without RA. It is important to realise that our definition was not RA classified by a rheumatologist and misclassification could have occurred.
Another limitation of this study is that even though we did find significant differences between the different groups, the ORs were only small. The clinical use of those small differences should be interpreted with caution. Moreover, the present analysis was cross-sectional and therefore, the causality of our findings cannot be claimed.

Unfortunately, we did not yet have access to genetic information about our participants, even though this is seen as an important factor for determining the switch to RA. ${ }^{37}$ Furthermore, our data on joint complaints was limited. It would have been helpful if more specific RA symptoms were assessed at baseline. Also data on breast feeding, ${ }^{38}$ birth weight, ${ }^{39}$ interstitial lung disease, ${ }^{40} \mathrm{C}$ reactive protein ${ }^{41}$ and other relevant autoantibodies like RF and anti-carbamylated protein (CarP) antibodies $^{42}$ were not available.

To our knowledge, this is the first study that measured ACPA in >40000 participants from a general, mostly Caucasian population.

As the Lifelines study is a prospective longitudinal cohort study with 30-year follow-up duration, it will be possible to gain follow-up information on our study population. It will be interesting to see which participants will eventually develop RA. Will the participants who reported having RA but did not yet have defined RA develop defined RA? These future results from the Lifelines cohort study will help us in improving the existing 
Table 6 Univariable and multivariable logistic regression for RA risk factors and ACPA positivity ( $\geq 6.2 \mathrm{U} / \mathrm{mL})$ in all participants and after exclusion of RA participants

\begin{tabular}{|c|c|c|c|c|c|c|}
\hline & \multicolumn{2}{|c|}{ Univariable } & \multirow[b]{2}{*}{$\mathrm{p}$ Value } & \multicolumn{2}{|c|}{ Multivariable } & \multirow[b]{2}{*}{ p Value } \\
\hline & OR & $95 \% \mathrm{Cl}$ & & $\overline{O R}$ & $95 \% \mathrm{Cl}$ & \\
\hline \multicolumn{7}{|l|}{ All participants ( $n=40136$ ) } \\
\hline Gender (female) & 1.342 & 1.092 to 1.649 & 0.005 & 1.325 & 1.069 to 1.643 & 0.010 \\
\hline Smoking: pack years & 1.023 & 1.015 to 1.030 & $<0.001$ & 1.018 & 1.009 to 1.026 & $<0.001$ \\
\hline \multicolumn{7}{|l|}{ Pack years, categories (\%) } \\
\hline$>10-20$ & 1.136 & 0.835 to 1.546 & 0.416 & & & \\
\hline$>20$ & 2.311 & 1.763 to 3.030 & $<0.001$ & & & \\
\hline \multicolumn{7}{|l|}{ Smoking status } \\
\hline Never smoker & Ref. & Ref. & Ref. & & & \\
\hline Former smoker & 1.532 & 1.221 to 1.923 & 0.000 & & & \\
\hline Self-reported RA & 15.083 & 11.800 to 19.281 & $<0.001$ & & & \\
\hline Defined RA & 92.404 & 64.953 to 131.456 & $<0.001$ & & & \\
\hline \multicolumn{7}{|l|}{ Participants with RA excluded ( $n=39$ 298) } \\
\hline Age (years) & 1.010 & 1.001 to 1.020 & 0.032 & 1.003 & 0.993 to 1.014 & 0.517 \\
\hline Gender (female) & 1.211 & 0.962 to 1.524 & 0.104 & 1.289 & 1.014 to 1.639 & 0.038 \\
\hline Smoking: pack years & 1.019 & 1.010 to 1.028 & $<0.001$ & 1.019 & 1.009 to 1.028 & $<0.001$ \\
\hline \multicolumn{7}{|l|}{ Pack years, categories (\%) } \\
\hline Never to 10 & Ref. & Ref. & Ref. & & & \\
\hline$>10-20$ & 1.070 & 0.752 to 1.524 & 0.706 & & & \\
\hline$>20$ & 1.915 & 1.379 to 2.659 & $<0.001$ & & & \\
\hline \multicolumn{7}{|l|}{ Smoking status } \\
\hline
\end{tabular}

Data are presented as ORs and Cls of the enter method. Forward and backward analyses resulted in comparable models with the same variables.

ACPA, anticitrullinated protein antibodies; RA, rheumatoid arthritis.

prediction models for RA, in order to facilitate early recognition of RA and act on it even in the early 'window of opportunity'.

In conclusion, this large, cross-sectional, population-based study in 40136 mostly Caucasian Lifelines participants showed that the prevalence of ACPA-CCP2 positivity is $1.0 \%$ for the total population and $0.8 \%$ when excluding patients with RA (ACPA cut-off $\geq 6.2 \mathrm{U} / \mathrm{mL}$ ). The strong association of ACPA positivity with RA and joint complaints supports the importance of ACPA screening in persons with joint/musculoskeletal complaints. Moreover, older age and smoking were associated with ACPA positivity and possibly play a pathogenic role in the development of ACPA positivity.

Acknowledgements The authors thank the Lifelines Cohort Study for its services, the contributing research centres delivering data to Lifelines, and all the study participants.

Contributors All authors were involved in drafting the article or revising it critically for important intellectual content. AvZ, SA and EB had full access to all of the data in the study and take responsibility for the integrity of the data and the accuracy of the data analysis. Study conception and design: AvZ, SA, CR, PCL, LAT, REMT,
TWJH, HB, EB. Acquisition of data; AvZ, SA, CR, PCL, FM, EB. Analysis and interpretation of data; AvZ, SA, CR, PCL, FM, LAT, REMT, TWJH, HB, EB.

Funding This study was supported by the Dutch Arthritis Association, by an in-kind grant from ThermoFisher Scientific as part of the IMI JU funded project BeTheCure, contract no. 115142-2 and by a grant from Biobanking and Biomolecular Research Infrastructure (BBMRI)-NL complementation projects.

The Lifelines Cohort Study, and generation and management of GWAS genotype data for the Lifelines Cohort Study is supported by the Netherlands Organization of Scientific Research NWO (grant 175.010.2007.006), the Ministry of Economic Affairs, the Ministry of Education, Culture and Science, the Ministry for Health, Welfare and Sports, the Northern Netherlands Collaboration of Provinces (SNN), the Province of Groningen, University Medical Center Groningen, the University of Groningen, Dutch Kidney Foundation and Dutch Diabetes Research Foundation.

Patient consent Obtained.

Ethics approval Local ethics committee of the UMCG.

Provenance and peer review Not commissioned; externally peer reviewed.

Data sharing statement All data are available in the Lifelines database https:/l www.lifelines.nl/.

Open Access This is an Open Access article distributed in accordance with the Creative Commons Attribution Non Commercial (CC BY-NC 4.0) license, which 
permits others to distribute, remix, adapt, build upon this work non-commercially, and license their derivative works on different terms, provided the original work is properly cited and the use is non-commercial. See: http://creativecommons.org/ licenses/by-nc/4.0/

\section{REFERENCES}

1 Firestein GS. Evolving concepts of rheumatoid arthritis. Nature 2003:423:356-61.

2 Heidari B. Rheumatoid Arthritis: cEarly diagnosis and treatment outcomes. Caspian J Intern Med 2011;2:161-70.

3 van Nies JA, Krabben A, Schoones JW, et al. What is the evidence for the presence of a therapeutic window of opportunity in rheumatoid arthritis? A systematic literature review. Ann Rheum Dis 2014:73:861-70.

4 van de Stadt $L A$, Witte $B I, B o s$ WH, et al. A prediction rule for the development of arthritis in seropositive arthralgia patients. Ann Rheum Dis 2013;72:1920-6.

5 Bos WH, Wolbink GJ, Boers M, et al. Arthritis development in patients with arthralgia is strongly associated with anti-citrullinated protein antibody status: a prospective cohort study. Ann Rheum Dis 2010;69:490-4.

6 van Steenbergen HW, van Nies JA, Huizinga TW, et al. Characterising arthralgia in the preclinical phase of rheumatoid arthritis using MRI. Ann Rheum Dis 2015;74:1225-32.

7 Nam JL, Hunt L, Hensor EM, et al. Enriching case selection for imminent RA: the use of anti-CCP antibodies in individuals with new non-specific musculoskeletal symptoms-a cohort study. Ann Rheum Dis 2016;75:1452-6.

8 Seegobin SD, Ma MH, Dahanayake C, et al. ACPA-positive and ACPA-negative rheumatoid arthritis differ in their requirements for combination DMARDs and corticosteroids: secondary analysis of a randomized controlled trial. Arthritis Res Ther 2014;16:R13.

9 De Rooy DP, Willemze A, Mertens B, et al. Can anti-cyclic citrullinated peptide antibody-negative RA be subdivided into clinical subphenotypes?. Arthritis Res Ther 2011;:13:R180

10 van der Helm-van Mil AH, Verpoort KN, Breedveld FC, et al. Antibodies to citrullinated proteins and differences in clinical progression of rheumatoid arthritis. Arthritis Res Ther 2005; 7:R949-58.

11 Jørgensen KT, Wiik A, Pedersen M, et al. Cytokines, autoantibodies and viral antibodies in premorbid and postdiagnostic sera from patients with rheumatoid arthritis: case-control study nested in a cohort of Norwegian blood donors. Ann Rheum Dis 2008;67:860-6.

12 Ioan-Facsinay A, Willemze A, Robinson DB, et al. Marked differences in fine specificity and isotype usage of the anti-citrullinated protein antibody in health and disease. Arthritis Rheum 2008;58:3000-8.

13 Goeldner I, Skare TL, de Messias Reason IT, et al. Anti-cyclic citrullinated peptide antibodies and rheumatoid factor in rheumatoid arthritis patients and relatives from Brazil. Rheumatology (Oxford) 2010;49:1590-3.

14 Barra L, Scinocca M, Saunders S, et al. Anti-citrullinated protein antibodies in unaffected first-degree relatives of rheumatoid arthritis patients. Arthritis Rheum 2013;65:1439-47.

15 Rantapää-Dahlqvist $\mathrm{S}$, de Jong BA, Berglin E, et al. Antibodies against cyclic citrullinated peptide and IgA rheumatoid factor predict the development of rheumatoid arthritis. Arthritis Rheum 2003:48:2741-9.

16 Nielen MM, van Schaardenburg D, Reesink HW, et al. Specific autoantibodies precede the symptoms of rheumatoid arthritis: a study of serial measurements in blood donors. Arthritis Rheum 2004:50:380-6.

17 Kolfenbach JR, Deane KD, Derber $L A$, et al. A prospective approach to investigating the natural history of preclinical rheumatoid arthritis (RA) using first-degree relatives of probands with RA. Arthritis Rheum 2009;61:1735-42.

18 Stack RJ, Sahni M, Mallen CD, et al. Symptom complexes at the earliest phases of rheumatoid arthritis: a synthesis of the qualitative literature. Arthritis Care Res (Hoboken) 2013:65:1916-26.

19 Gerlag DM, Raza K, van Baarsen LG, et al. EULAR recommendations for terminology and research in individuals at risk of rheumatoid arthritis: report from the Study Group for Risk Factors for Rheumatoid Arthritis. Ann Rheum Dis 2012;71:638-41.

20 Terao C, Ohmura K, Ikari K, et al. Effects of smoking and shared epitope on the production of anti-citrullinated peptide antibody in a Japanese adult population. Arthritis Care Res (Hoboken) 2014;66:1818-27.
21 Tasliyurt T, Kisacik B, Kaya SU, et al. The frequency of antibodies against cyclic citrullinated peptides and rheumatoid factor in healthy population: a field study of rheumatoid arthritis from northern Turkey. Rheumatol Int 2013;33:939-42.

22 Hensvold AH, Frisell T, Magnusson PK, et al. How well do ACPA discriminate and predict RA in the general population: a study based on 12590 population-representative Swedish twins. Ann Rheum Dis 2016: Published Online First 28 April 2016.

23 Källberg H, Ding B, Padyukov L, et al. Smoking is a major preventable risk factor for rheumatoid arthritis: estimations of risks after various exposures to cigarette smoke. Ann Rheum Dis 2011;70:508-11.

24 Sparks JA, Chang SC, Deane KD, et al. Associations of smoking and age with inflammatory joint signs among unaffected first-degree relatives of rheumatoid arthritis patients: results from studies of the etiology of rheumatoid arthritis. Ann Rheum Dis 2016;68:1828-38.

25 Gerlag DM, Norris JM, Tak PP. Towards prevention of autoantibody-positive rheumatoid arthritis: from lifestyle modification to preventive treatment. Rheumatology (Oxford) 2016:55:607-14.

26 Scholtens S, Smidt N, Swertz MA, et al. Cohort Profile: lifelines, a three-generation cohort study and biobank. Int J Epidemiol 2015:44:1172-80.

27 Klijs B, Scholtens S, Mandemakers JJ, et al. Representativeness of the lifelines cohort study. PLOS ONE 2015;10:e0137203.

28 Brennan P, Silman A. Why the gender difference in susceptibility to rheumatoid arthritis? Ann Rheum Dis 1995;54:694-5.

29 Yahya A, Bengtsson C, Lai TC, et al. Smoking is associated with an increased risk of developing ACPA-positive but not ACPA-negative rheumatoid arthritis in Asian populations: evidence from the Malaysian MyEIRA case-control study. Mod Rheumatol 2012;22:524-31.

30 Sparks JA, Chen CY, Hiraki LT, et al. Contributions of familial rheumatoid arthritis or lupus and environmental factors to risk of rheumatoid arthritis in women: a prospective cohort study. Arthritis Care Res (Hoboken) 2014:66:1438-46.

31 de Pablo P, Dietrich T, Chapple IL, et al. The autoantibody repertoire in periodontitis: a role in the induction of autoimmunity to citrullinated proteins in rheumatoid arthritis?. Ann Rheum Dis 2014;73:580-6.

32 Scott IC, Tan R, Stahl D, et al. The protective effect of alcohol on developing rheumatoid arthritis: a systematic review and meta-analysis. Rheumatology (Oxford) 2013:52:856-67.

33 Costenbader KH, Feskanich D, Mandl LA, et al. Smoking intensity, duration, and cessation, and the risk of rheumatoid arthritis in women. Am J Med 2006;119:503. e1-e9.

34 Rosell M, Wesley AM, Rydin K, et al. Dietary fish and fish oil and the risk of rheumatoid arthritis. Epidemiology 2009;20:896-901.

$35 \mathrm{Hu}$ Y, Costenbader $\mathrm{KH}$, Gao X, et al. Sugar-sweetened soda consumption and risk of developing rheumatoid arthritis in women. Am J Clin Nutr 2014;100: 959-67.

36 Neovius M, Simard JF, Askling J, et al. Nationwide prevalence of rheumatoid arthritis and penetration of disease-modifying drugs in Sweden. Ann Rheum Dis 2011;70:624-9.

37 Jutley G, Raza K, Buckley CD. New pathogenic insights into rheumatoid arthritis. Curr Opin Rheumatol 2015;27:249-55.

38 Chen H, Wang J, Zhou W, et al. Breastfeeding and risk of rheumatoid arthritis: a systematic review and metaanalysis. J Rheumatol 2015;42:1563-9.

39 Mandl LA, Costenbader KH, Simard JF, et al. Is birthweight associated with risk of rheumatoid arthritis? Data from a large cohort study. Ann Rheum Dis 2009;68:514-18

40 Kelly CA, Saravanan V, Nisar M, et al. Rheumatoid arthritis-related interstitial lung disease: associations, prognostic factors and physiological and radiological characteristics—a large multicentre UK study. Rheumatology (Oxford) 2014:53:1676-82.

41 Nielen MM, van Schaardenburg D, Reesink HW, et al. Increased levels of C-reactive protein in serum from blood donors before the onset of rheumatoid arthritis. Arthritis Rheum 2004;50:2423-7.

42 Shi J, Knevel R, Suwannalai $P$, et al. Autoantibodies recognizing carbamylated proteins are present in sera of patients with rheumatoid arthritis and predict joint damage. Proc Natl Acad Sci USA 2011;108:17372-7. 